\title{
Primary Fibro Sarcoma of the Heart
}

\author{
Serbeze Kabashi',2, Naim Hoxha1, Shkelzen Gashi', Ilir Ahmegjekaj', Ilir Bejta1, Muharrem Sadiku', Halit Ymeri'1,2, \\ Antigona Kabashi', Xhavit Bicaji,2, Sefedin Mucaj ${ }^{2}$ \\ Department of Radiology, Diagnostic Centre, UCCK, Pristine, Kosovo ${ }^{1}$ \\ Faculty of Medicine, Pristine University, Pristine, Kosovo²
}

Corresponding author: Serbeze Kabashi, MD. Department of radiology, UCCK, Prishtine, Kosovo. E-mail: sebikabashi@gmail.com

\section{Case report} ABSTRACT

Primary malignant heart tumors represen rare entities where fibro sarcoma represents about $3 \%$ of all. Introducing the patient: A 15 years old patient with cardiac insufficiency (heart failure) symptoms, such as weakness, cyanosis, palpitations and breathing difficul ties; enlargement of upper mediastinum and pleural effusion. Through echocardiography a pericardial effusion and intracavitary thrombus in atrium was diagnosed. With computed tomography is diagnosed a tumoral mass in right atrium which is also spread in the right ventricle of the heart. Tumor is completely removed; pat histology result showed primary fibro sarcoma of the heart. At that time no metastasis was found. Conclusion. Primary malignant heart tumors may manifest like cardiac insufficiency or like systemic dis- eases. Fibrosarcomas are rare and have bad prognosis. On average patients can live around six months after initial symptoms appeared and diagnosis of the tumor was done. In the case of cardiac insufficiency with differential diagnosis we should also think of heart tumors, which could certainly be proved for or eliminated by echocardiography.

Key words: Heart, tumors, fibro sarcoma, insufficiency, diagnosis, echocardiography.

\section{INTRODUCTION}

Findings about heart tumors were initially provided by Bonet in $18^{\text {th }}$ century $(1,2)$. In 1936 first successful resection of cardiac tumor was performed (3). Depending on their origin heart tumors are classified in two main groups. First group consists of tumors that originate from heart tissues and thus are known as primary tumors whereas the second groups consist of secondary tumors which represent different malignant tumor metastasis that originate from others tissues and body organs. Primary heart tumors are very rare entity. According to autopsy results and surgical interventions their incidence is around $0.001-0.28$ (3) while heart metastasis are 10-50 times more frequent $(1,3,4,6)$. About $75 \%$ of primary heart tumors are benign whereas others are malign. $(2,3)$. Sarcomas make about $75 \%$ of primary malign heart tumors (6) of which the most common one is angiosarcoma.

Fibrosarcomas are very rare tumors and make only about $3 \%$ of primary malignant heart tumors (4). In the following section we present a patient diagnosed with primary fibro sarcoma of the heart.

\section{INTRODUCING THE CASE:}

A 15 years old male patient, on the last week of September 2012, is hospitalized at the Pediatrics Clinic at the University Clinical Centre in Kosovo (UCCK) on the intensive care unit. He was showing some nonspecific symptoms and signs such as weakness, fever; headache, nausea for about three weeks and gradually his situation worsen.

At the moment of check in the patient was cyanotic and had face edema particularly in the per orbital region. With heart and lung auscultation it was found that heart beat was weakened but rhythmical while breathing noise was weakened. He-

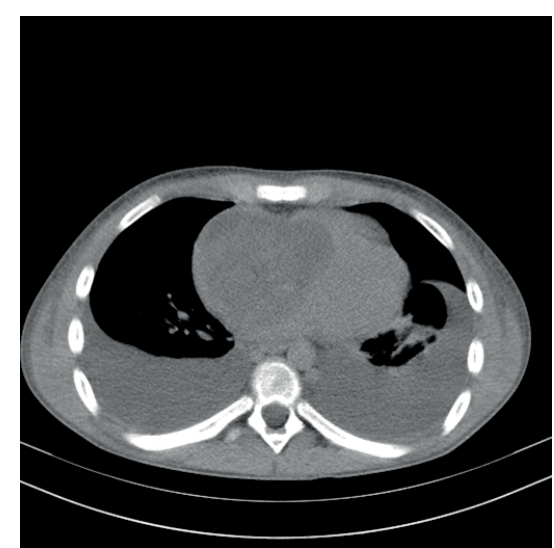

Figure 1. CT of thorax without i.v. contrast Axial plane

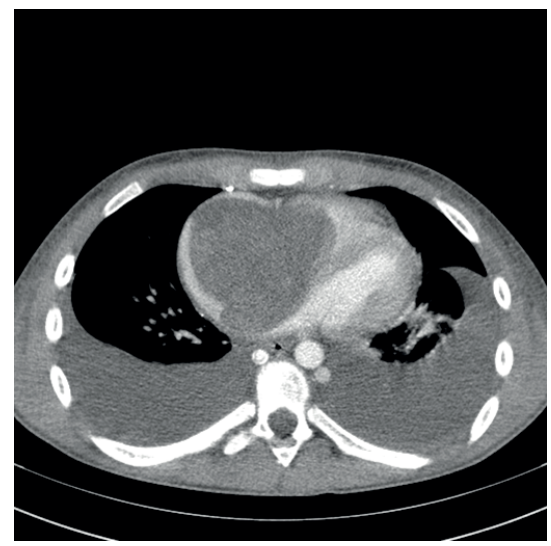

Figure 2. CT of thorax with i.v. contrast Axial plane

moglobin saturation was $67 \%$, and arterial pressure was $80 \times 60 \mathrm{mmHg}$.

Lab data: WBC - 12.6, RBC - 5.08, Hgb - 14.3, Hct - 41.5,PLT. - 188, MCV - 81.8, Gli - 4.8, ALT - 11, AST - 16, Chol. - 2.5, CK - 40. Direct Bil. - 8.9, Total Bil. - 28.5, LDH - 507, Urea - 4.7, Urine: Prot. ++, Le. - 17. In the thorax radiography the PA view found pleural effusion of the left side and enlargement of upper mediastinum mainly on the right side of $\mathrm{v}$. cava superior and v. azygos region. The ECG registered a sinusal rhythm with a rate about $100 / \mathrm{min}$, decreased voltage and AV block of grade I. With the transthoracic echocardiogram was 


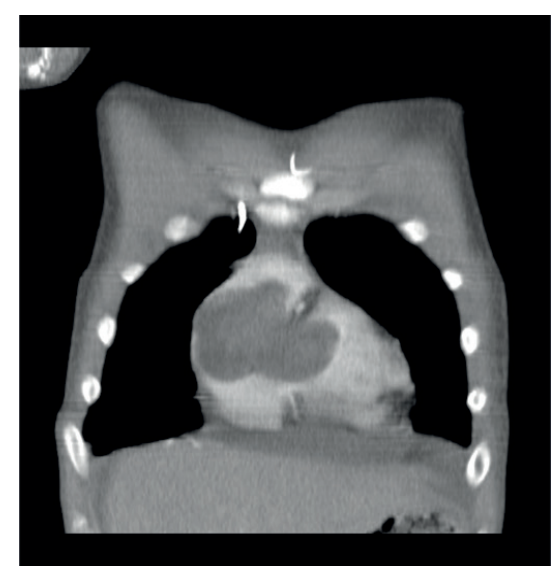

Figure 3. CT of thorax with i.v. contrast Coronal plane

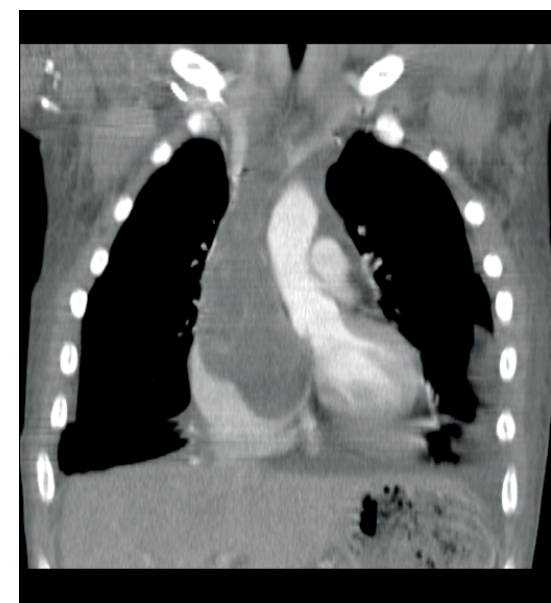

Figure 4. CT of thorax with contrast, Coronal plane

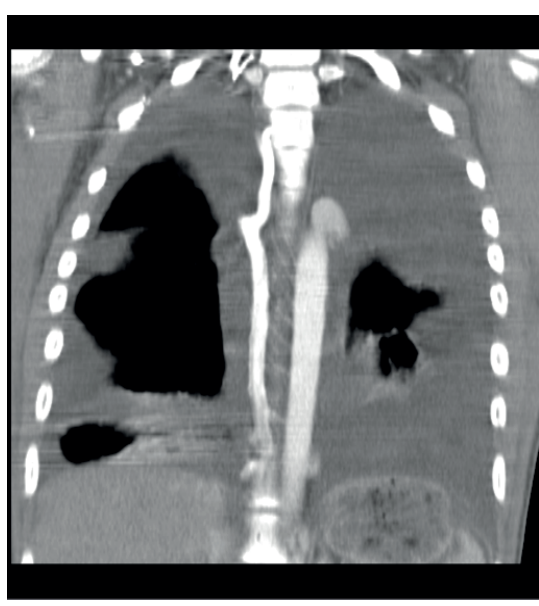

Figure 5. CT of thorax with i.v. contrast. Coronal plane

found pericardial effusion, stasis on systemic veins and decrease of circulation on pulmonary artery. It is also found a hyperechogenic mass that nearly covers the right atrium and spreads towards the right ventricle, which was thought it represented a massive intracavitary thrombus. The patient was referred to the Radiology Clinic; a computed tomography of thorax with and without i.v. contrast was conducted. In this case a hyperdensity mass was observed and the majority of which after applying the contrast it showed a tumoral mass. This mass filled up almost all of the right atrium, which was widened and pressured the left atrium (Figure 1 and 2).

We also observe a spread on the right ventricle through ostium atrioventricular and an extension up on the superior caval vein, brachiocefalica dex. vein and jugularis dex. vein, and thus causing their dilatation (Figure 3 and 4).

On the axial plane the maximum diameter of the intra-arterial septum of this mass was $7 \times 8.5 \mathrm{~cm}$. In the pleural space there is a massive bilateral effusion. A greater enlargement of veins was also discovered which anastomose two kava veins: vena mammaria interna and vena azygos (Figure 5 and 6). No metastases were found. Free fluid is observed in the abdominal segment included in this

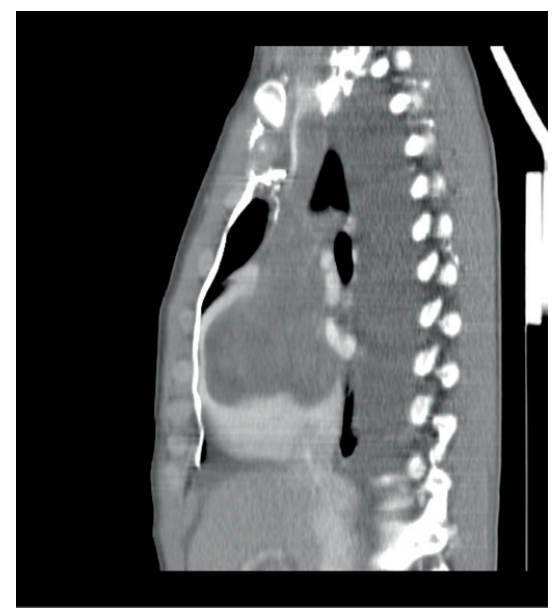

Figure 6. CT of thorax with i.v. contrast. Sagittal plane

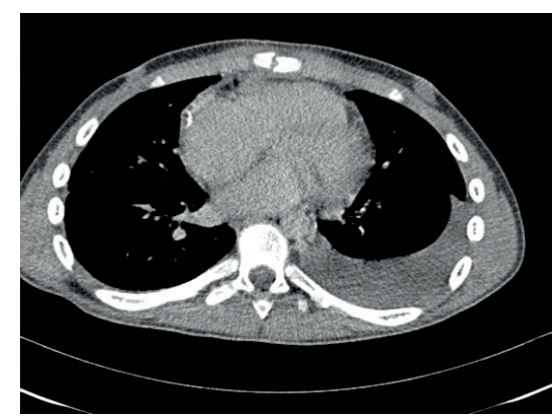

Figure 7. CT of thorax with i.v. contrast (post surgery)

examination.

The patient was referred to a specialized Cardio-surgical centre in Tirana where he underwent a surgical intervention. The histopathological analysis proved that this was a case with fibrosarcoma tumor. A month

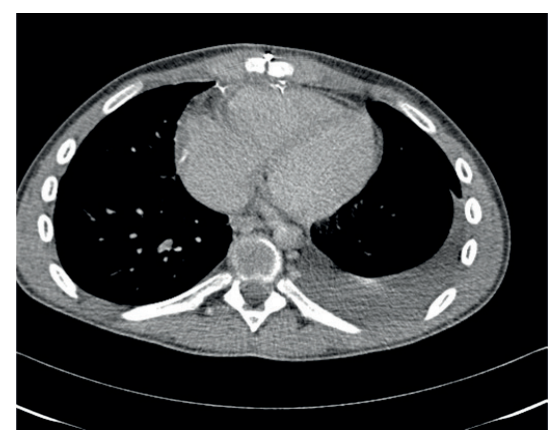

Figure 8. CT of thorax with i.v. contrast (post surgery)

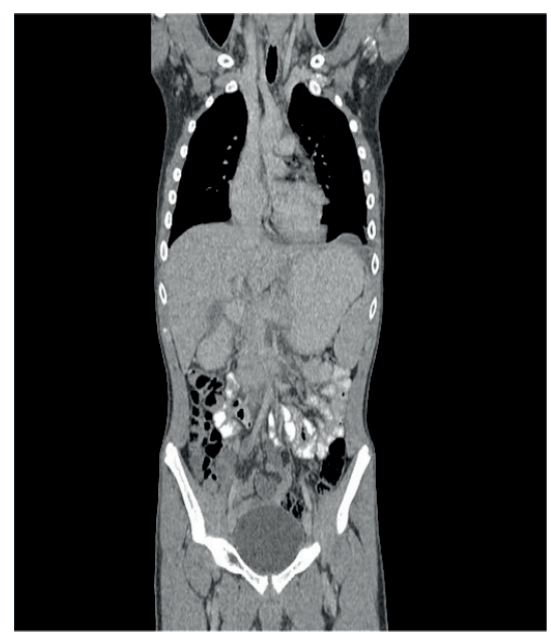

Figure 9. CT of thorax, abdomen and pelvic with i.v. contrast - Coronal plane

and a half after the surgery another CT of thorax, abdomen and pelvic was conducted with an i.v. contrast (Figure 7, 8 and 9).

A pleural effusion was found on the left side. Pericardial effusion was also found. No signs of secondary mass were identified.

\section{DISCUSSION}

Heart tumors represent a big challenge when diagnosing them. Their clinical symptoms are nonspecific, and depend more on the size and location of tumor than on its histologic type. (6) They are caused by four main mechanisms: intracavitary enlargement of tumor can cause obstruction of blood circulation or malfunction of heart valves; local invasion of tumor can cause arrhythmia and pericardial effusion; a part of tumor can embolise and cause cerebrovascular and peripheral vascular accidents. Also, when tumor releases cytokines (IL-6) it can cause systemic or constitutional symptoms of weight loss, fever, arthralgia, myalgia, hemolytic anemia, thrombocytopenia, leukocytosis, elevation of CRP, faster SE $(2,6)$. 
Primary heart sarcomas are found with people of all group ages, but more often in the 3-5 decade of their life with no observable gender differences (4). Our patient is 15 years old male. Primary heart sarcomas are usually found on the right atrium, and frequently are angiosarcomas (6).

Sarcomas found on the right side of heart usually infiltrate more, grow in the shape of cauliflower, and metastasize earlier compared to sarcomas located on left side of heart $(6$, $7)$. In our case we are dealing with a massive tumor located on the right atrium that spreads on the right ventricle towards vena cava superior, but no metastasis where found at the moment of diagnosis. Also, sarcoma located on right side of the heart rarely causes congestive heart insufficiency or disorderly hemodynamic status compared to left side sarcomas, which are very symptomatic at the moment of presentation $(6,7)$. In our case we have symptoms of heavy right side heart insufficiency NYHA III.

Through thorax radiography we can get nonspecific data. In our case we represented a widening of upper mediastinum and pleural effusion.

Echocardiography plays an important role on diagnosing heart tumors. It enables us to see the tumor, measure it, observe its location, movement and place where it is fixed. A computed tomography plays an important role in diagnosing heart tumors and allows us to see other thorax structures. In our case, through echography, the described mass is reported as thrombus. Also, it is also reported a pericardial effusion which was not observed in CT.

Magnetic resonance is very important in diagnosing heart tumors, too. We were not able to apply it because of patient's difficult situation.
Surgical intervention and complete tumor resection is main treatment. In case of malignant tumors chemotherapy and radiotherapy are applied too.

Primary malignant heart tumors which often attack young people have very bad prognosis: without a surgical intervention, survival between 9 to 12 months is $10 \%$ (6).

\section{CONCLUSIONS}

Heart tumors are rare; fibro sarcoma makes about 3\% of all malignant heart tumors. Their diagnosis is very difficult not only because of their rareness but also because of their nonspecific clinical symptoms. In cases of acute heart insufficiency, in a differential diagnosis, we should suspect a heart tumor whereby every patient should be checked with echography. Heart sarcomas have bad prognosis; about a year after the diagnosis was made. Surgical excision, even if partial, is indicated for the purpose of decreasing symptoms of obstruction. In some cases of non-surgical sarcomas good results are achieved by heart transplanting.

\section{REFERENCES}

1. Lam KY, Dickens P, Chan AC. Tumors of the heart. A 20-year experience with a review of 12485 consecutive autopsies. Arch Pathol Lab Med. 1993 Oct; 117(10): 1027-1031.

2. Vander Salm TJ. Unusual primary tumors of the heart. Semin Thorac Cardiovasc Surg. 2000 Apr; 12(2): 89100.

3. Rodriguez-Cruz E. Pediatric cardiac tumors; http emedicine.medscape. com . /article 901147- overview. Accessed june 2013.

4. Sabolic J, Klemenc M, Kosuljandic V. Primary fibrosarcoma of the heart. Zdrav Vestn. 2001; 70: 643-
646.

5. Becker AE. Primary heart tumors in the pediatric age group: a revew of salient pathologic features relevant for clinicians. Pediatr Cardiol. 2000 Jul-Aug; 21(4): 317-323.

6. Leja MJ, Shah DJ, Reardon MJ. Primary Cardiac Tumors. Tex Heart Inst J. 2011; 38(3): 261-262.

7. Vaporciyan A, Reardon MJ. Right heart sarcomas. Methodist Debakey Cardiovasc J. 2010 Jul-Sep; 6(3): 4448.

8. Blackmon SH, Patel A, Reardon MJ. Management of primary cardiac sarcomas. Expert Rev Cardiovasc Ther. 2008 Oct; 6(9): 1217-1222.

9. Knobel B, Rosman P, Kishon Y, Husar M. Intracardiac primary fibrosarcoma. Case report and literature review. Thorac Cardiovasc Surg. 1992 Aug; 40(4): 227-230.

10. Narasimhan S. Unexplained Constitutional Symptoms, Weight Loss and the Heart. Journal of Medical Sciencies Research, November 15, 2007; 2.

11. Devbhandari MP, Meraj S, Jones MT, Kadir I, Bridgewater B. Primary cardiac sarcoma: reports of two cases and a review of current literature. Journal of Cardiothoracic Surgery 2007; 2: 34 doi:10.1186/1749-8090-234.

12. Kim JT, Baek WK, Kim KH, Yoon YH, Kim DH, Lim HKA. Primary cardiac sarcoma preoperatively presented as a benign left atrial myxoma. Yonsei Med J. 2003 Jun 30; 44(3): 530-533.

13. Damjanovic M. Djordjevic-Radojkovic D. Perisic Z, Apostolovic S, Koracevic G, Tomasevic M, Pavlovic M, Jankovic R. Heart failure caused by cardiac rhabdomyosarcoma. Kardiol Pol. 2008 Nov; 66(11): 1207-1209. 